pressure only " when the heart has come to the very end of its tether"; in my experience it is much more common. These points can, however, be reserved for further discussion. I am, Sirs, yours faithfully,

Edinburgh, Feb. 14th, 1903. William Russelt.

\section{THE ABUSE OF MEDICAL CHARITY.}

\section{To the Editors of THE LANCET.}

SIRS,-The defence of the administration of the Bradford Children's Hospital, published by the honorary secretary, Mr. H. J. Jeffery, in The LANCET of Feb. 7th, p. 398, to the charges made by the chairman of the Bradford board of guardians, calls for notice. It is not a little remarkable that $\mathrm{Mr}$. Jeffery does not make the slightest reference to your leading article on the abuses at that hospital, but only refers to the charges of the chairman of the guardians. The same policy of silence was pursued in 1898, when your Special Commissioner made a report on the hospital abuse in Bradford, the Children's Hospital being very severely criticised. Then, as now, the board of that hospital took no notice whatever of your criticism and the abuses have continued unabated. Such tactics may to some extent prevent that attention being drawn to the flagrant abuse of the charity which would be caused by an attempted defence of the hospital management against your criticism. But it cannot fail to suggest the idea of inability to make a successful defence, and it certainly produces a very unfarourable opinion of the board when one sees that it is content to lie under the serious charge of mismanagement of trust funds without one word of protest. There may be times when "silence is golden," but to preserve the attitude of deaf-mutism when one is publicly charged with allowing charitable funds to be recklessly squandered is not usually regarded as dignified or proper. Such an attitude is indeed startling.

It is rather clever of $\mathrm{Mr}$. Jeffery not to mention in his letter to you the charges brought against his board. This careful suppression tends to obliterate them from memory, and on reading his defence cursorily one might imagine that an injured innocent had been accused of-nothing in particular. But on contrasting his defence with the accusations it will be seen how inadequate it is. Indeed, Mr. Jeffery virtually admits the truth of all Mr. F. H. Bentham's charges. What Mr. Bentham is reported to have said about the Children's Hospital, in his general condemnation of the management of all our hospitals, is as follows: "The Children's Hospital has no recommendations. Children were taken into the institution without inquiry into the circumstances of the parents, though they were required afterwards, if able, to contribute. He was told that in every case the parents' word was taken, and he was not aware that any inquiries had been made through the C.O.S. [Charity Organisation Society]. The committee received $£ 104$ from that source in 1901 for 213 children with an average attendance of $37 \cdot 2$ days. In the out-patient department 2308 cases were dealt with. No inquiries were made into the circumstances and all comers were dealt with indiscriminately."

As Mr. Jeffery does not make any reference in his defence to any of these various points, except that as to "inquiry into the circumstances" of applicants for medical charity, it may be assumed he admits they are all correctly statedviz., (1) that the paltry sum of $£ 104$ was collected from parents of children who spent 7781 sick days in hospital; (2) that there were 2308 out-patients and that no inquiry is made about them unless "deemed necessary "by the board; (3) that the board does not avail itself of the assistance of the Charity Organisation Society ; (4) that all comers are indiscriminately treated; and (5) the parents' word is accepted in practically all cases. It requires some attention to see that in Mr. Jeffery's letter he is throughout only dealing with the 213 in-patients, except where he once refers to "all" patients.

Now, what is Mr. Jeffery's defence? 1. He says: "Very many of the cases treated at the hospital [i.e., in-patients, T. W. H.] are received on the recommendation of medical gentlemen in the town who naturally satisfy themselves that the position of the families is such as to justify an appeal to the charity." In other words the board makes no inquiry as to "very many of the cases." The assumption that the medical men who send these cases act as inquiry officers could be no justification for the board's neglect. The assumption is further no doubt quite unwarranted. Medical $\mathbf{m} \in \mathbf{n}$ do not act as inquiry agents as to their own patients and certainly will not do it to relieve the board of its auty. What "very many" cases means is uncertain. I would ask Mr. Jeffery if it means as much as 1 in 100 ; until I have his assurance $I$ must doubt if it means so many. 2. "The bulk of the in-patients," he says, "are drafted into the hospital by the honorary medical staff from the out-patients' department, after careful examination and inquiry as to the circumstances of each family"; in other words, he says, the honorary staff are the inquiry officers of the hospital, their inquiries are made while prescribing for the applicants, and their investigations are thorough and satisfactory. How completely is the nature of a proper inquiry understood by Mr. Jeffery and his board if he thinks such an inquiry sufficient! How utterly has the medical staff sunk from the dignity of their profession, if as Mr. Jeffery alleges, while actually prescribing for the sick and suffering they engage in a minute inquisition of the means of the sufferers. I can say of one member of the staff that he indignantly repudiates having ever acted such an odious part as that of combined medical officer and charity organisation officer. Supposing the medical officers did stoop to this meanness, which I will not readily believe, they must accept the statements of the parents alone, as Mr. Bentham said.

It is obvious that the board does not take proper steps to safeguard the charitable funds intrusted to it. No doubt the staff will take occasion to repudiate the statement that they act as inquiry officers. I believe $\mathrm{Mr}$. Jeffery is misinformed as to the facts. No reference was made by $\mathrm{Mr}$. Bentham to the great abuse arising from the enormous number of quite trivial cases treated at this hospital (and at all the Bradford hospitals) or of the unnatural rate of increase of the number of patients, which has been out of all proportion to the increase of the population and the wealth of the city.

I am, Sirs, yours faithfully,

Bradford Feb. 10th, 1903.

Thos. WhITESIDE HrME.

\section{THE ANATOMY OF GLÉNARD'S DISEASE.}

\section{To the Editors of THE LANCET.}

SIRS,-Dr. John Knott has been good enough to criticise in your pages ${ }^{1}$ and at considerable length a recent effort of mine to explain the manner in which the abdominal viscera become displaced. The explanation which I offered has proved entirely unsatisfactory to Dr. Knott, especially in so far as it has upset certain preconceptions of his regarding the nature and action of the diaphragm. Amongst these preconceptions is that of the "relative immobility" of the central or cordiform tendon of the diaphragm. On the solitary occasion in which Dr. Knott had an opportunity of studying the movements of the diaphragm by the aid of the $x$ rays he would have found had he fixed the screen and divided it into inch squares, that it was he and not the "accomplished physicist" that was deceived by the movements of the ribs. If he will take the trouble to examine the first ten subjects that come to hand he will find that the movements of the middle and lateral leaflets of the diaphragm correspond to the measurements given in $\mathrm{my}$ lecture. The experience will also convince Dr. Knott that it is a dangerous thing to generalise from a rough guess made on a single instance.

Dr. Knott cites the phenomena to be seen in a hiccoughing boy as irrefutable evidence of the relative immobility of the central tendon of the diaphragm. I followed minutely his directions for the production of hiccoughing as regards boy, bribe, and oatmeal, but failed to produce it in any one of the six individuals investigated. Whether the failure was due to the inhibition of expectancy or to some further error of observation on the part of Dr. Knott I cannot say. There can be no doubt, however, that he is perfectly right in asserting that in hiccoughing the central part of the diaphragm is relatively immobile although he is apparently quite unaware of the cause of the immobility. At the commencement of a hiccough, as may be seen in the illuminated body, all the muscular fibres of the diaphragm, both costal and spinal, suddenly contract and attempt to jerk the central tendon downwards. Its descent is arrested and it remains locked by the sudden 
closure of the glottis. When the glottis is opened the central tendon again resumes its ordinary respiratory mobility. I am indebted to Dr. Knott for calling my attention to the phenomena of hiccoughing, for it provides another instance of the accuracy of my "preposterous explanation" of the action of the diaphragm. On inspiration the diaphragm expends its force in three directions: (1) in pushing the abdominal viscera forwards and downwards; (2) in drawing the viscera of the thorax in corresponding directions; (3) in raising the abdominal ends of the lower six pairs of ribs (with the exception of the twelfth). In normal respiration the diaphragm assists the external intercostals in elevating the costal margin, but if, as in hiccoughing, the thoracic and abdominal viscera are rendered immoveable, the force of the diaphragm is spent, as Dr. Knott so clearly demonstrates, in drawing the abdominal ends of the lower ribs upwards and inwards-that is to say, the diaphragm draws its moveable costal insertion towards its firm spinal margin, a movement which Dr. Knott says is impossible to understand.

In dealing with the cause of the variability in the position of the diaphragm in dead subjects I inferred that the diaphragm after death represented the phase of ccmplete expiration. To that inference Dr. Knott apparently takes no exception, but my statement that "the elasticity of the lungs draws the diaphragm up as far as it will yield" appears to him "in the present state of physical and anatomical knowledge to read rather funny." "It is unnecessary," he proceeds, "of course, to point out that the lungs, or their elasticity, have no direct connexion with the diaphragm." Thereupon Dr. Knott makes certain observations on the stacdard of physiological knowledge he would require of tyros and rapidly becomes mathematical. Now when a man, in dealing with some simple problem in physiology or natural history, becomes mathematical it will be found that, in nine cases out of ten, he is trying to prove the existence of something that is not, and to this rule my critic is no exception. I need not quote for Dr. Knott that the elasticity of the lungs after death, if modern text-books on physiology are trustworthy, is enough to support a column of mercury from two to five millimetres high; I would rather beg him to leave his study chair for the post mortem room and to verify certain experiments which I have carried out there for his benefit. The experiments are designed to show that the elasticity of the lungs have a great deal to do with the position of the diaphragm. In five subjects varying in age from six months to 52 years the trachea was connected with a manometer. In each case there were no pleuritic adhesions. Three long hat-pins were inserted in a row perpendicular to the surface of the chest, one with its point buried in the viscera of the right dome, one in the left dome, and one in the middle inserted only in a costal cartilage, so as to serve as an index of the movements of the other two when the chest was opened. Dr. Knott knows as well as I do that the very partial collapse of the lung which follows an incision in the walls of the thorax was not due to atmospheric pressure, for on opening the chest the pressure is then the same on both suriaces of the lung, but is due entirely to its elasticity. The only factor annihilated by opening the chest is the elasticity of the lung. In the five cases I measured the elasticity varied from 0.5 to $3 \mathrm{Hg} \mathrm{mm}$. As the lungs collapsed and their elastic traction disappeared the domes of the diaphragm and the abdominal viscera within them descended from two to five millimetres. The degree of descent roughly corresponds with the amount of pulmonary elasticity. Perhaps when Dr. Knott ccmes to repeat those experiments the idea of the elasticity of the lungs having something to do with the position of the diaphragm may strike him as less " funny" than it did.

My description of the diaphragm as a fan shaped digastric muscle, rising from the upper lumbar region of the spine and inserted on the abdominal ends of the lower six ribs appears to Dr. Knott a "preposterous" and "physicometaphysical statement." The statement will strike him in quite a different sense when he becomes better acquainted with the origin, nature, structure, and action of the diaphragm. If he approves of the name "digastric" for the muscle which goes by that designation in the neck he cannot legitimately withhold it from the diaphragm, for in nature, in origin, in manner of developement and in action these two muscles correspond point for point.

I have tried to show Dr. Knott that "preposterous" is a dangerous word to employ; its use denotes ignorance more frequently than knowledge.

Feb. 16th, 1903.

I am, Sirs, yours faithfully, ARTHUR KEITH

\section{THE VIRCHOW MEMORIAL.}

\author{
To the Editors of THE LANCET.
}

SIRs,-Allow me to inform your readers that the subscrip. tion list for the Virchow memorial will close at the end of the present month. So far, 97 subscribers have contributed £225 1s. 6d. Further contributions should be sent before Feb. 28th to the honorary treasurer of the Virchow Memorial, care of Messrs. Robarts, Lubbock, and Co., 15, Lombardstreet, London, E.C.

$$
\text { I am, Sirs, yours faithfully, }
$$

FELIX SEMON

Wimpole-street, W., Feb. 16th, 1903. Honorary Secretary.

\section{A QUESTION IN INEBRIETY. \\ To the Editors of THE LANCET.}

SIRs, - In our dealings with inebriates it is an interesting question for us to consider whether we have really to deal with a class of individuals whose will power is a weak or a strong feature of their minds. The accepted belief is that the inebriate is a weak-willed creature, but a gcod deal of experience of inebriates has led me to doubt that idea and rather to believe that which I consider to be a fact-i.e., that the inebriate is possessed of a will which over-rides the other faculties of his mind in so far at least as his appreciation of his moral obligations is concerned, and therefore that his will is the strongest feature in his mind.

From a psychological standpoint we may admit that when the will and the other faculties of the mind act in unison we have as the result a properly balanced intellect. In the inebriate we frequently observe these other faculties of the mind tending towards a high class of intellect, the latter form being, indeed, often fully revealed together with the tendency to inebriety. Should, however, those other faculties of the mind outrun the will to any great extent ccördination of the whole is lost and the reasconing powers justify to the mind acts and conceptions which the will is unable to restrain within recognised proper bounds and those aberrations of intellect occur which cause eccentricity and lunacy. On the other hand, should the will override these other faculties of the mind the balance again becomes lost and the inebriate, the spendthrift, the fanatic et hoo genus omne stalk in. We hear constantly of the inebriate who is desirous of giving up drink but that " his will is too weak." It really is that his will is too strong; his will to drink entirely outstrips those other faculties of his mind which present to him his moral obligations not to drink, the result being that such individual's act is the outcome of a major force of will and not that of a minor quantity of it. It is in this light, therefore, that I consider that the inebriate is possessed of an unfortunately strong-willed temperament and not, as generally accepted, a weak-willed one. I would be glad of the views of some of your readers as to this heterodox opinion which I beg to submit to you.

Feb. 13th, 1903 I am, Sirs, yours faithfully,

\section{THE LARGE INTESTINE AS AN INTER- MITTENT SYPHON.}

To the Editors of THE LANCET.

SIRs,-The publication of $\mathrm{my}$ paper on this subject has aroused so much interest that I should like to solicit the coöperation of your readers in helping me with some side issues and $\mathrm{I}$ am encouraged to do so by the signal success that has followed a similar attempt.

In the notes which I added to the reprint of the article in the Edinburgh Medical Journal and again in the address an abstract of which appeared in THE LANCET of Feb. 7th p. 374, I proved as far as could be done by reasoning that the longitudinal bands of the large intestine are normally in a state of continuous tonic contraction. But, having no facilities for observation, I wrote to Dr. T. G. Brodie, of the Examination Hall physiological laboratories, and requested him to look out for this phenomenon. I received his answer on Jan. 31st and his eonclusion was expressed in these words : "I think there is no question whatever but that the longitudinal bands of the colon are tonically contracted." 